\title{
Energy Detection Approach for Spectrum Sensing in Cognitive Radio Systems
}

\begin{tabular}{|c|c|c|}
\hline \multicolumn{3}{|c|}{ Rüstem YILMAZEL $^{* 1}$, Muhammet Nuri SEYMAN ${ }^{1,}$ Eyüp TUNA ${ }^{2}$} \\
\hline $\begin{array}{r}{ }^{1} \text { Kirlkkale Univer } \\
{ }^{3} \text { Kırlkkale University,Faculty of }\end{array}$ & $\begin{array}{l}\text { irlkkale Vocational High Schoo } \\
\text { ering,Department of Electrical }\end{array}$ & $\begin{array}{l}\text { Irtment Kırıkkale, TURKEY } \\
\text { ectronics Engineering, Kırıkkale, TURKEY }\end{array}$ \\
\hline Başvuru/Received: 15/03/2018 & Kabul/Accepted: 06/15/2018 & Son Versiyon/Final Version: 29/06/2018 \\
\hline
\end{tabular}

\begin{abstract}
Because a large number of licensed users have occasionally used their allocated bandwidth in recent years, efficient use of frequency band is a vital issue. While licensed users continue to use this bandwidth for publishing, unused bands can be allocated for reuse to provide broadband network services. These empty bands are described as white space and cover a large part of the bandwidth. It is possible to activate this great potential by cognitive radio technology. In this study, energy detection technique was used to detect unused bands. With this technique, it is determined which frequency band is suitable and there will be done appropriately the assignment of the second user.
\end{abstract}

\section{Key Words}

“Cognitive radio, energy detection method neyman-pearson approach, , spectrum sensing” 


\section{INTRODUCTION}

Since wireless communication is used very intensely nowadays, the radio frequency band has been subjected to intensity. Traffic in the narrow frequency band has steadily increased due to its widespread use of technologies such as Wi-Fi, Bluetooth and GPS. According to the US Federal Communications Commission (FCC), the results has shown that the radio frequency band is not used actively and appropriately (S. Haykin, D.J.Thompson, J.H.Reed, 2009). Since this band belonging to the licensed user has not been used outside of a certain time, spectrum holes have appeared in the frequency band. If these bands that are not used much by the licensed user are allowed for dynamic access, the use of these bands by other communication systems may preclude the problem of spectrum inefficiency. The system to do this is called cognitive radio technology.

This technology was first found by Mitola. In his study, cognitive radio is defined that a system that alters the operating parameters to allow broadcasting in this spectrum by finding the empty spectrum (J. Mitola G. Q. Maguire, 1999). In cognitive radio technology, the primary user is called that the frequency band belongs to itself and user having priority to use spectrum. The secondary user is called that user using the empty frequency band without interfering to the licensed user. The main purpose of cognitive radio network is to enable unlicensed users to use these spectrum holes when licensed users are not active. In the meantime, the purpose is to provide the use of the spectrum efficiently without damaging the licensed user.

\section{COGNITIVE RADIO}

The major factor that led to the emergence of cognitive radio technology is to be the inefficiency in terms of use of the spectrum. According to a report issued by the Federal Communications Commission (FCC), spectrum hole ratio has changed from $15 \%$ to 85\% at some time of day (Federal Communications Commission, 2002). Cognitive radio technology, which allows the spectrum belonging to a licensed user to be used by unlicensed persons, detects the spectrum state thanks to spectrum detection techniques and allows dynamic spectrum access.

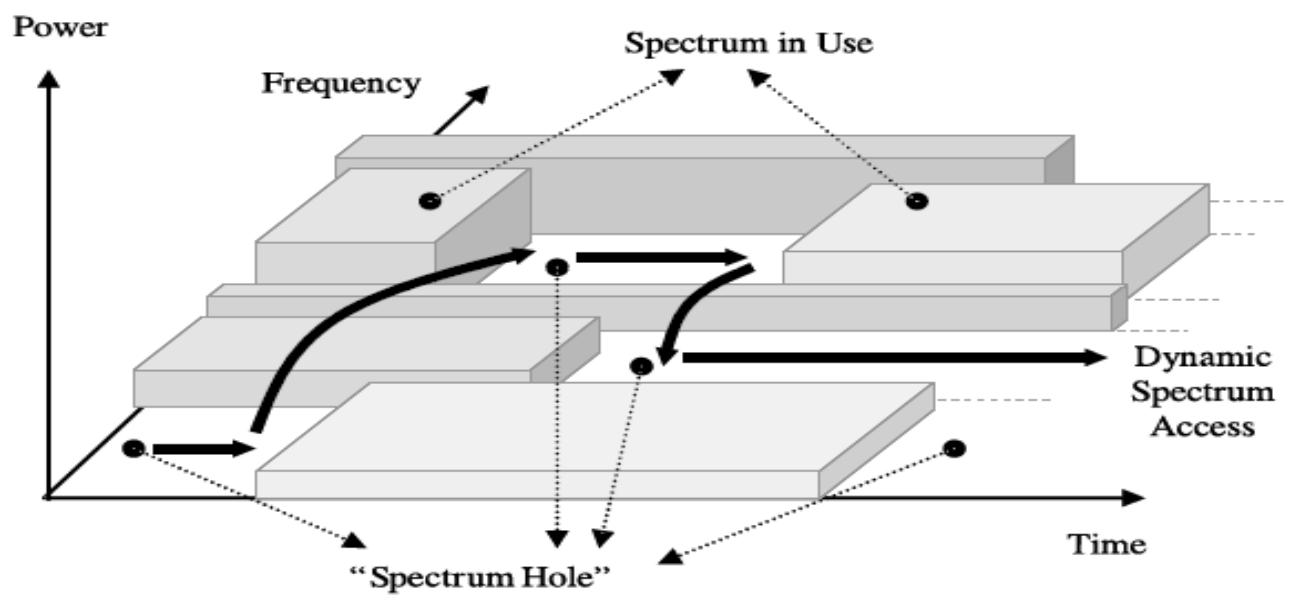

Fig. 1. Spectrum holes and dynamic spectrum access(Emrullah G, 2015)

Cognitive radio technology enables efficient use of bandwidth by different types of wireless network structure and different spectrum sensing techniques. Cognitive radio confronts some difficulties while it presents this technology. There are things to do to overcome them. Firstly, it is necessary to determine the parts that are not used in the frequency spectrum. After that the most suitable for use is assigned to these parts. Other users must be contacted before assignment to prevent a possible interference. Finally, if the licensed user logs into the channel, the unlicensed user must leave the spectrum without disturbing it. Overcoming these challenges consists of the steps of cognitive radio technology. Spectrum sensing, spectrum management, spectrum sharing and spectrum mobility constitute these steps (S. İngök, 2002).

Spectrum sensing involves mobility of the licensed user and the control of the spectrum by constantly analyzing the frequency. It determines the access methods to the spectrum without interfering with primary users by detecting unused spectrum and spectrum holes. It must examine the existence of licensed users while the spectrum is analyzed periodically (F.K. Jondral, 2005). One of the difficulties is the noise occurred in the frequency area during the detection of the licensed user signals. There are many techniques by performing spectrum sensing. The speed and accuracy of the results are the two most important factors in determining the optimum spectrum sensing algorithm. Depending on data obtained from the spectrum sensing, spectrum management is a decisionmaking process related to the time when the spectrum will be appropriate and variables related to frequency and spectrum to be used. These variables are the parameters that constitute service quality such as interference level, error channel ratio, path loss, link layer delay (E. Tuna, M.,Karagöz, 2012). One of important criterion in cognitive radio technology is to allow the frequency to be used without exposing the licensed user to interference when the spectrum is empty (C. Pham, N.H. Tran, C.T. Do, C, S. 
Moon, C.S. Hong, 2014). Spectrum management is formed two sections. The first section is to collect information about spectrum bands considering the statistical data of licensed networks. The second step is to determine which channel is empty and to assign it according to this obtained result. One of the problems encountered is to be incorrect results in the calculation of the spectrum capacity using SNR information.

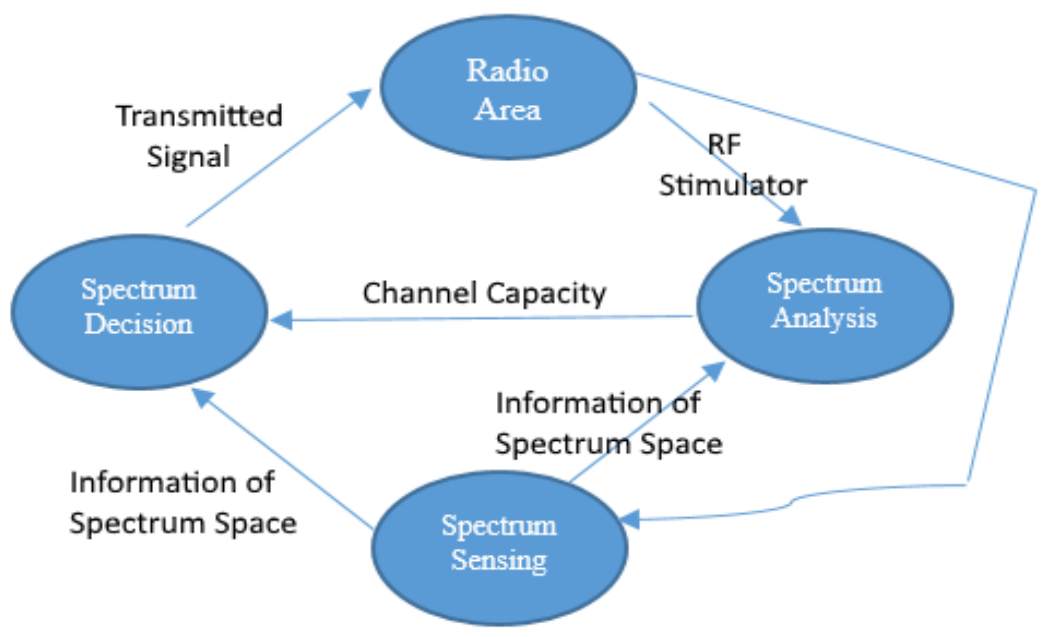

Fig. 2. Cognitive Radio Block Diagram

In spectrum sharing, coordination process to the appropriate channel with spectrum management during access of unlicensed users is performed. Spectrum sharing can be approached from different angles. If we look at it as an architectural structure, it can change according to the central or distributed. Another view may be according to the spectrum assignment attitude. This view occurs according to the knowledge obtained from one node is related to other nodes. Finally, it is processed according to the access technology. There are two techniques, overlay and underlay, in last part. In spectrum sharing, one of the disadvantages is that an unlicensed user leaves spectrum when licensed user want to use the spectrum (L. Khalid, A. Anpalagan, 2010). Spectrum mobility is to $\log$ in for licensed user's channel usage request or to leave from channel in bad channel conditions. Communication should continue because the frequency bands will change constantly. Whenever the operating frequency changes, the operating variables must also change. The most important success criterion is that the spectrum change is fast and without damaging the first user. It is shown how the stages are done in cognitive radio technology in figure 2 (A. Lertsinsrubtavee, A., Malouch, S. Fdid, 2014).

\section{ENERGY DETECTION TECHNIQUE}

This technique is the most common among spectrum sensing methods. It is preferred because it has few mathematical expressions and its hardware structure is not complicated. It is possible to use this technique for the licensed user without extra information. The output value of the energy detection is compare with a threshold value according to the variance of the noise signal. According to the resulting value, licensed user signal is detected. Energy detection technique also has some weaknesses. The most important disadvantage is to determine the threshold value. Another problem is interference with licensed user when unlicensed user is used frequency and sometimes not to distinguish the noise.

In this technique, unlicensed users determine licensed users based on the power of the signal. Since the detection process is based on the SNR value of the signal, the uncertainty of the noise signal will also affect the system performance (I.F. Akyildiz, W.Y. Lee, K.R. Chowdhury, 2009). The energy detection technique is based on the Neyman-Pearson approach. The purpose of this approach is to increase the probability of detection depending on false alarm probability. The probability of detection $\left(\mathrm{P}_{\mathrm{d}}\right)$ is that the output signal is greater than the threshold value when the primary user broadcasts. The probability of false alarm $\left(\mathrm{P}_{\mathrm{f}}\right)$ is that the output signal is greater than the threshold value when the primary user is not broadcasting. The incomplete detection probability $\left(\mathrm{P}_{\mathrm{md}}=1-\mathrm{P}_{\mathrm{d}}\right)$ is that the unlicensed user is unable to detect the licensed user. These probabilities, depending on the threshold used by the algorithm to determine if the signal is present or not, are defined as the receiver operating characteristic.

\section{MATHEMATICAL EQUATIONS}

In this study, the results were obtained by considering the AWGN channel. There are two possible situations. While $\mathrm{H}_{0}$ shows that there are no licensed users, $H_{1}$ shows that there are licensed users (S. Atapattu, C. Tellambura, H. Jiang, 2011).

$$
X[n]=\left\{\begin{array}{l}
W[n], H_{0} \\
s[n]+W[n], H_{1}
\end{array}\right\} n=1,2,3, \ldots
$$


Where $\mathrm{X}[\mathrm{n}]$ : an example of the signal coming to the cognitive radio user, $\mathrm{W}[\mathrm{n}]$ : AWGN signal with zero mean and variance $\sigma_{w}^{2}$, $\mathrm{S}[\mathrm{n}]$ is the signal with zero mean and variance and also is a received signal assuming that it is an independent random process. $\mathrm{N}$ : an example of the signal. The following equation 2 is used to find the signal to noise ratio (SNR) (S.Y. Lien, C.C. Tseng, K.C. Chen, 2008).

$S N R=\frac{\sigma_{S}^{2}}{\sigma_{w}^{2}}$

$P_{d}$ is expressed as in the following equation 3.

$P_{d}=Q\left[\frac{\gamma-N\left(\sigma_{w}^{2}+\sigma_{s}^{2}\right)}{\sqrt{2 N\left(\sigma_{w}^{2}+\sigma_{s}^{2}\right)^{2}}}\right]$

$Q($.) used in equations is general $\mathrm{Q}$ function. The number of samples to be found $(\mathrm{N})$ is shown as the following equation (4) to find the $P_{d}$ and $P_{f}$ variables corresponding to a given SNR (F.F. Digha, M.S. Alouini, M.K. Simon, 2007).

$$
N=2 S N R^{-2}\left[Q^{-1}\left(P_{f}\right)-(1+S N R) Q^{-1}\left(P_{d}\right)\right]^{2}
$$

\section{RESULTS}

AWGN channel was used for analysis in this study. it is shown how the magnitude of the SNR value affects the results.

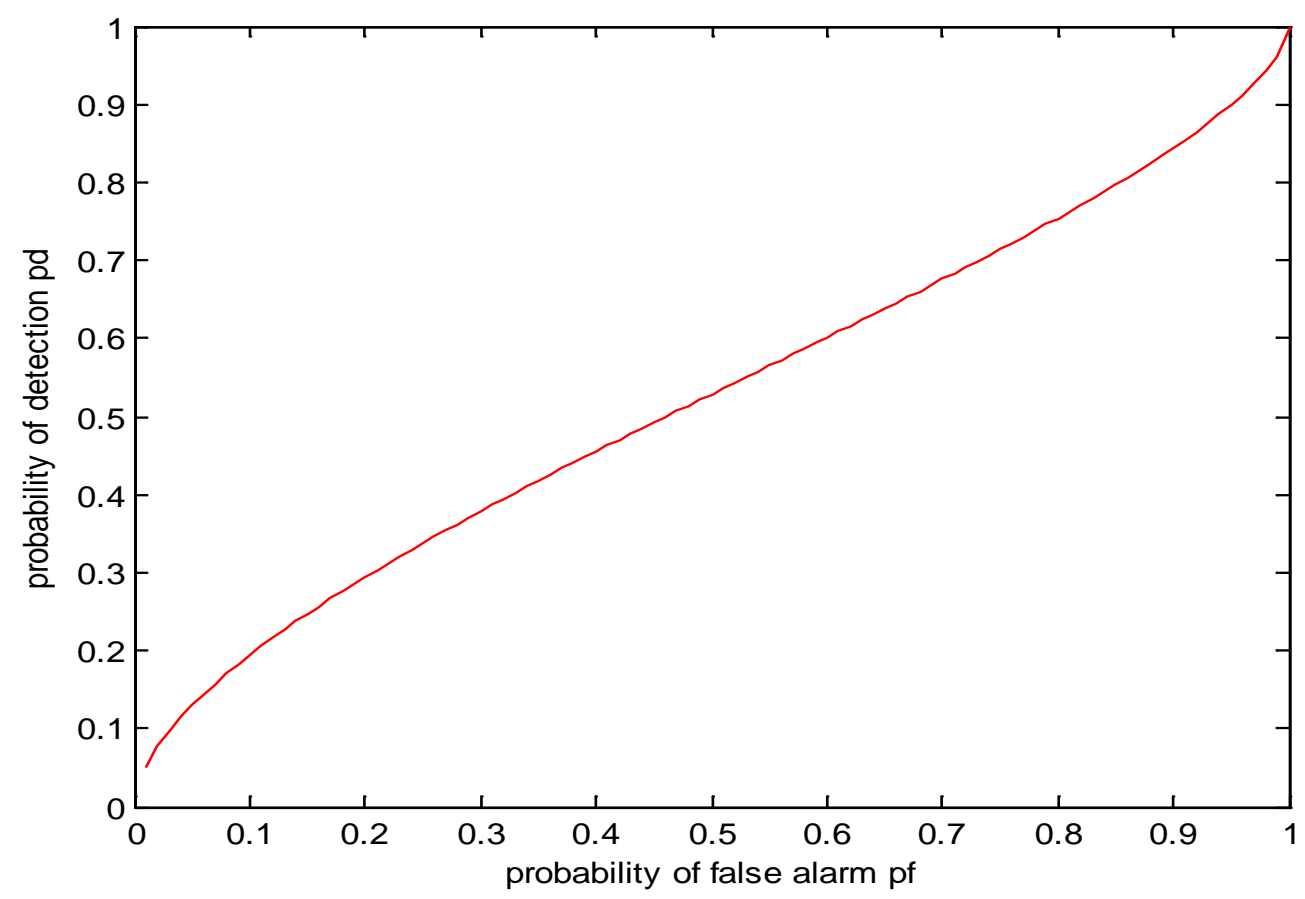

Fig. 3. Probability of detection compared to probability of false alarm for SNR $=15 \mathrm{~dB}$ 


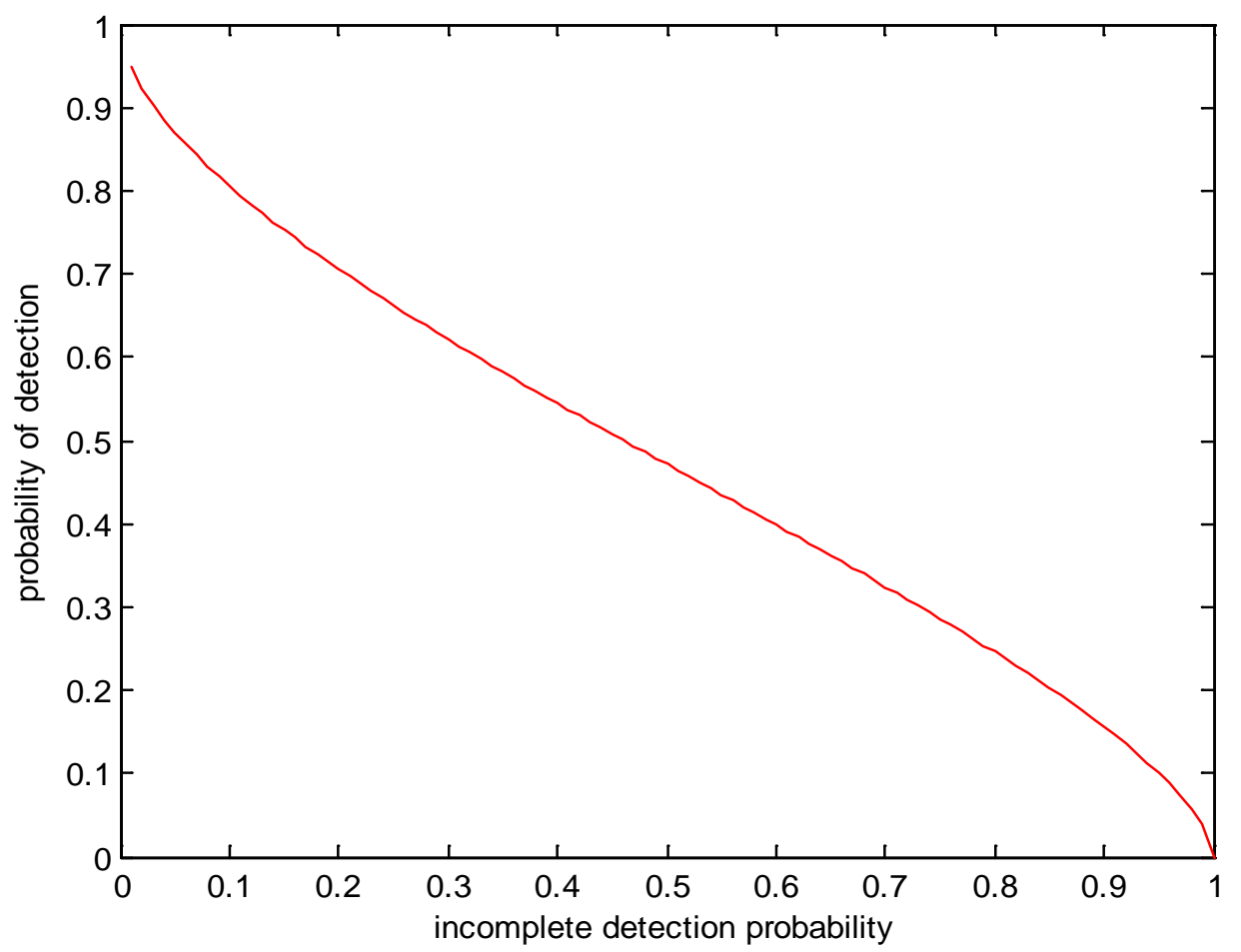

Fig. 4. Probability of detection compared to incomplete detection probability for SNR $=15 \mathrm{~dB}$

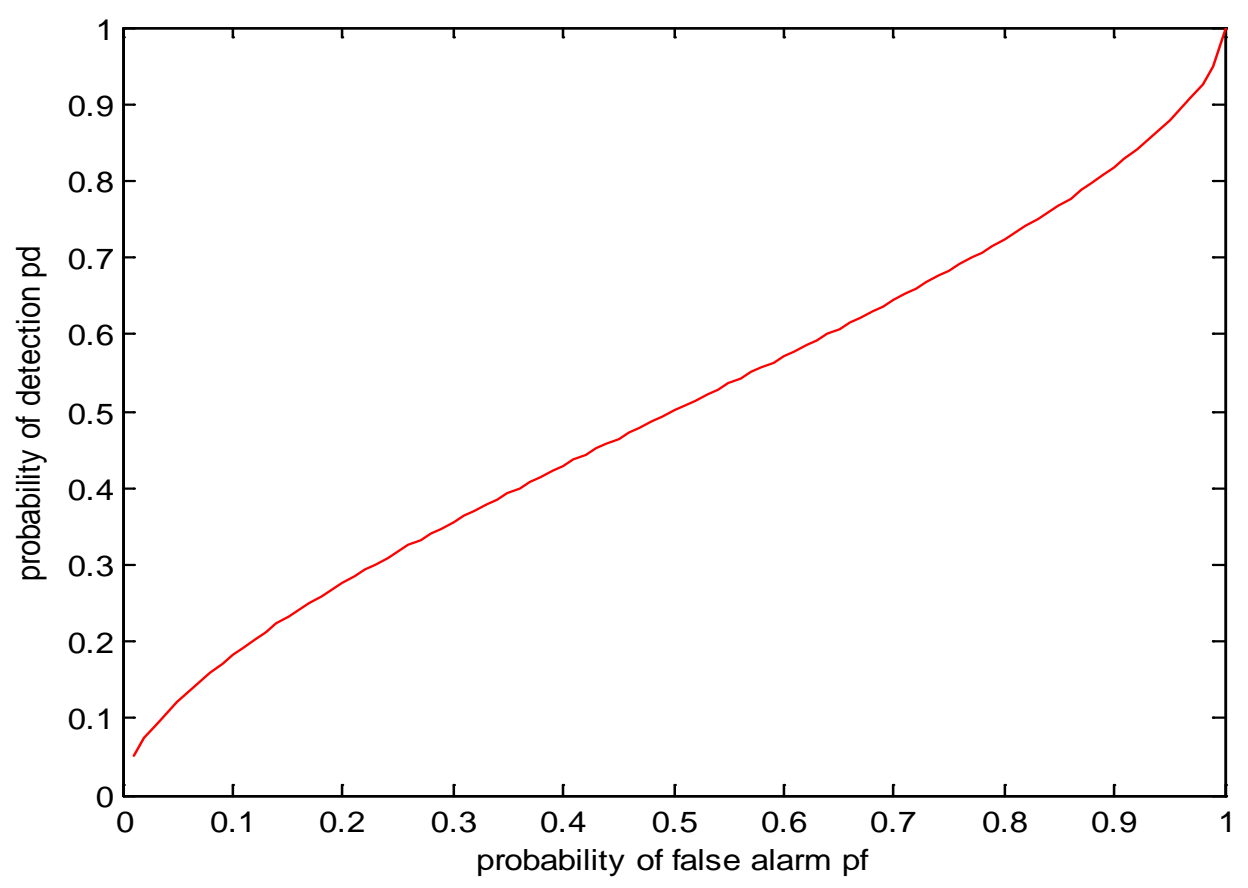

Fig. 5. Probability of detection compared to probability of false alarm for SNR $=40 \mathrm{~dB}$

Results to be obtained according to the Neyman-Pearson rule are evaluated according to detection probability $P_{d}$, false alarm probability $\mathrm{P}_{\mathrm{f}}$, the incomplete detection probability $\mathrm{P}_{\mathrm{md}}$ and probability of false alarm graphics. In this approach, the goal is to increase the probability of detection compared to false alarm probability. In figure 3 and figure 4 , it is possible to see that increases probability of detection compared to probability of false alarm while the SNR value is $15 \mathrm{~dB}$. 


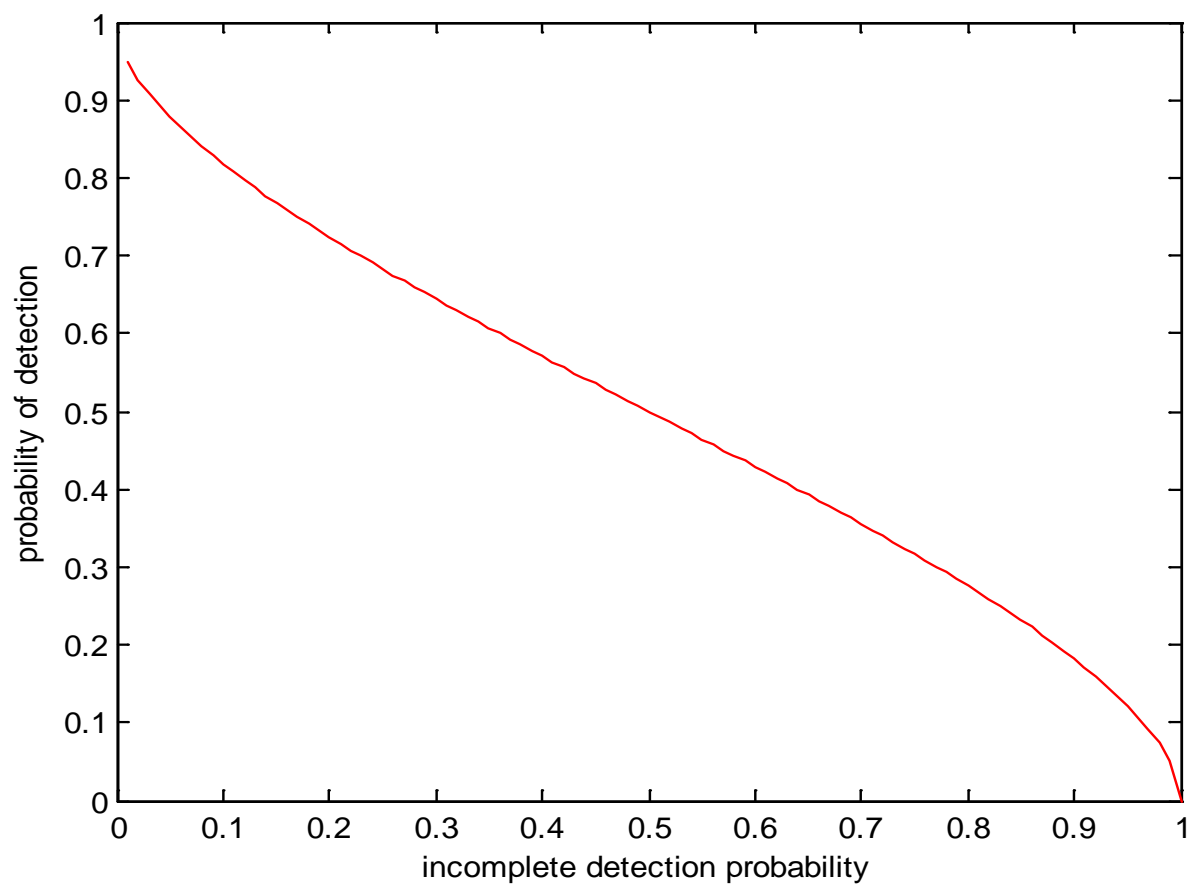

Fig. 6. Probability of detection compared to incomplete detection probability for SNR $=40 \mathrm{~dB}$

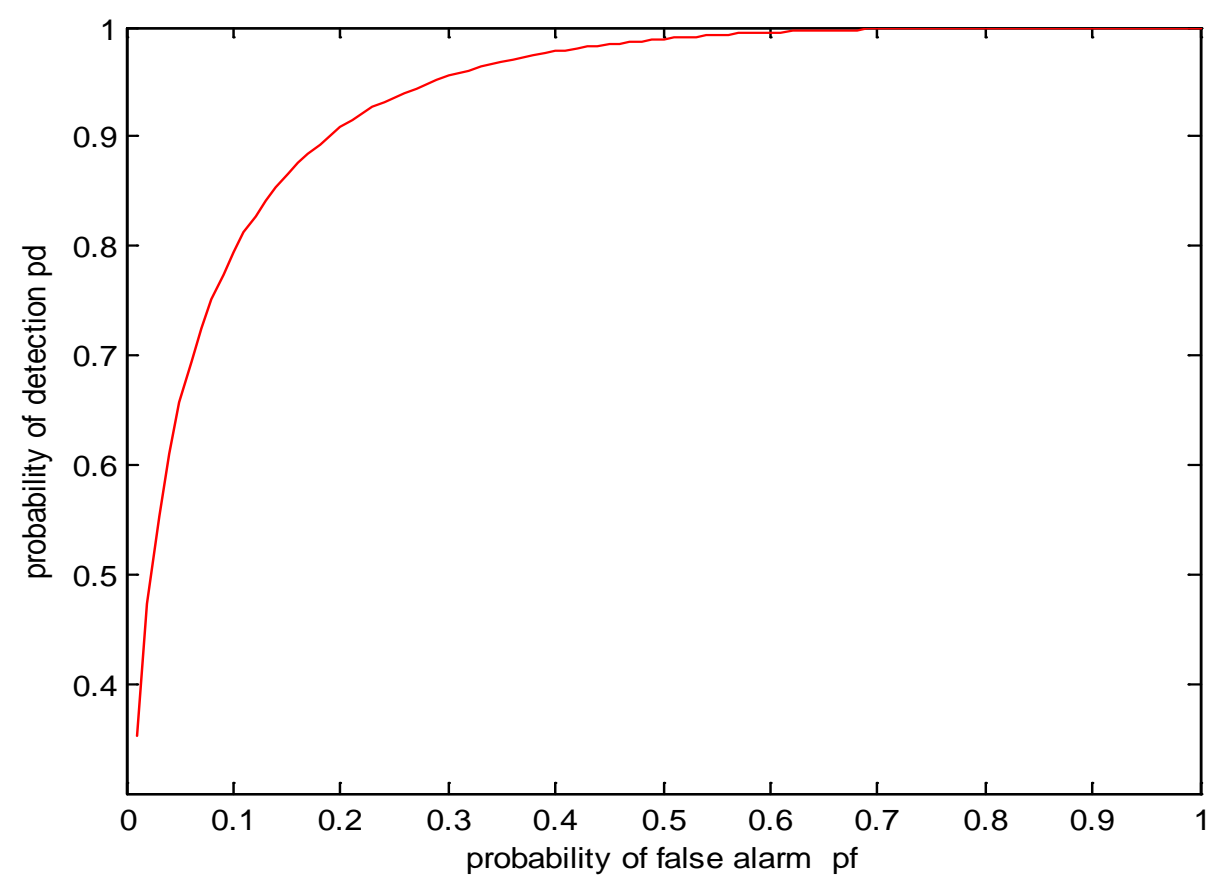

Fig. 7. Probability of detection compared to probability of false alarm for SNR $=2 \mathrm{~dB}$

In figure 5 and figure 6, it is possible to see that increases probability of detection compared to probability of false alarm while the SNR value is $40 \mathrm{~dB}$. In figure 7 and figure 8 , it is possible to see probability of detection compared to probability of false alarm while the SNR value is $2 \mathrm{~dB}$. However, errors have observed when the system has performed energy detection at small SNR values. The results corresponding to the different SNR values are shown in the figure 9 and figure 10. 


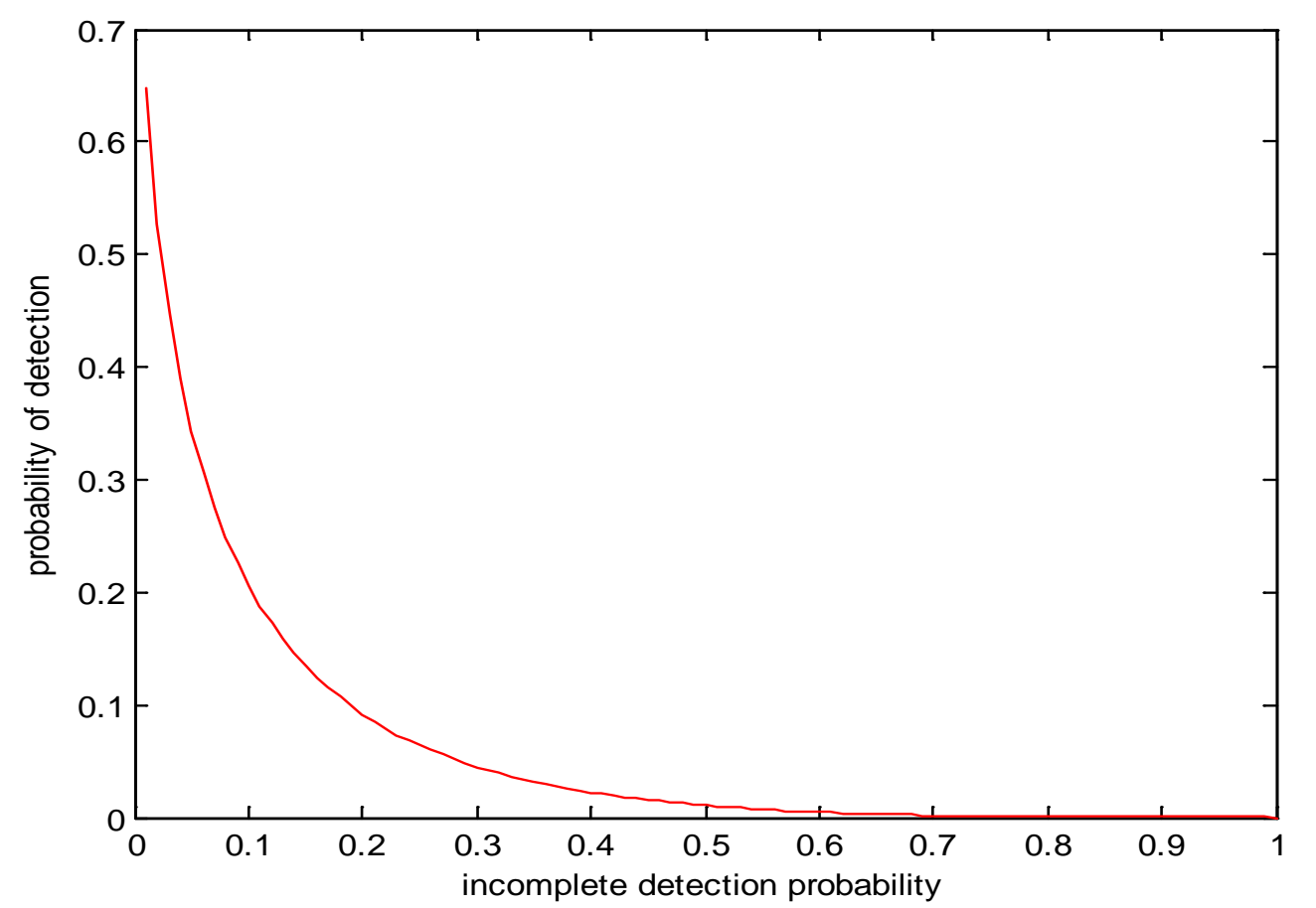

Fig. 8. Probability of detection compared to incomplete detection probability for $S N R=2 d B$

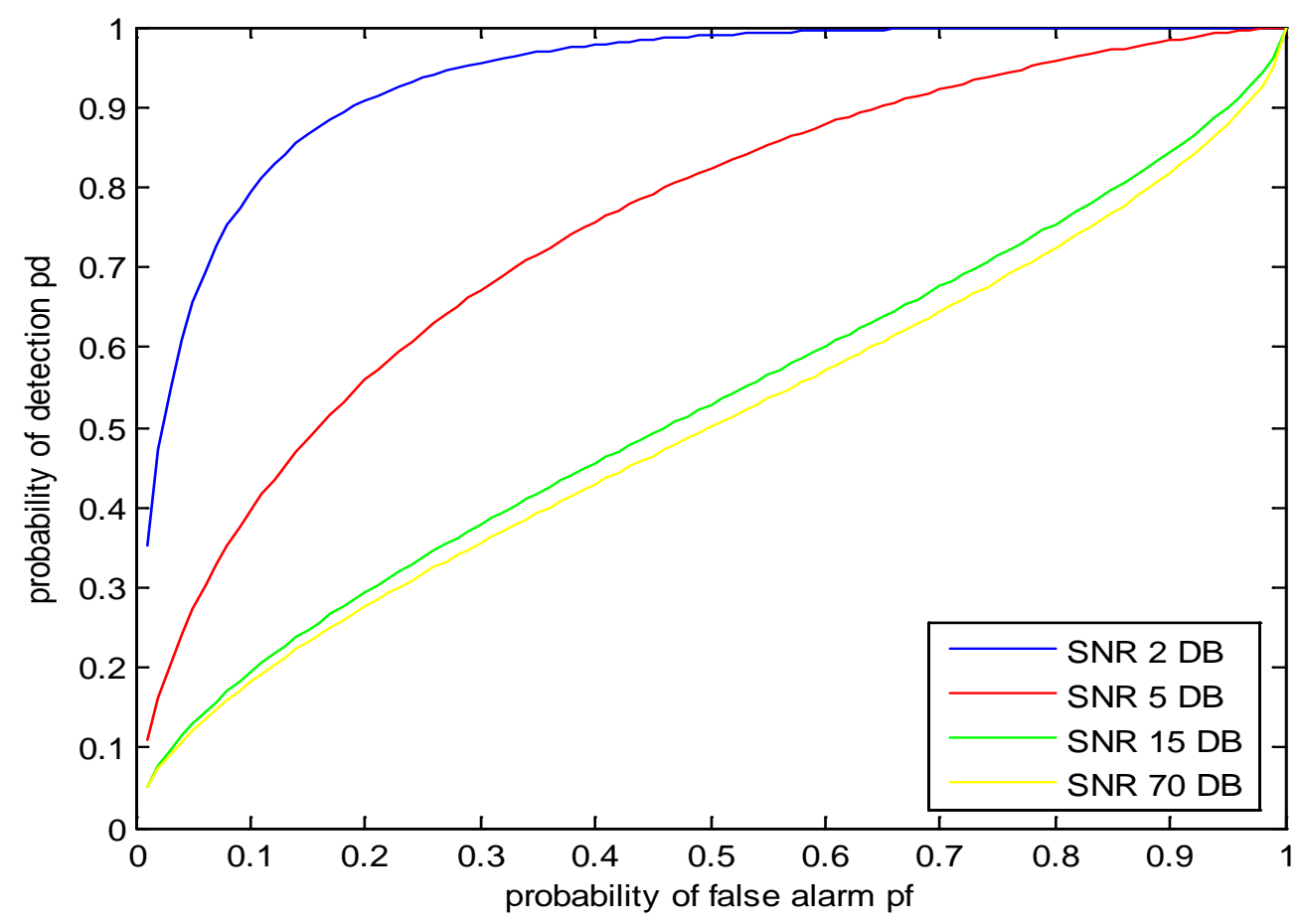

Fig. 9. Probability of detection compared to probability of false alarm for various SNRs 


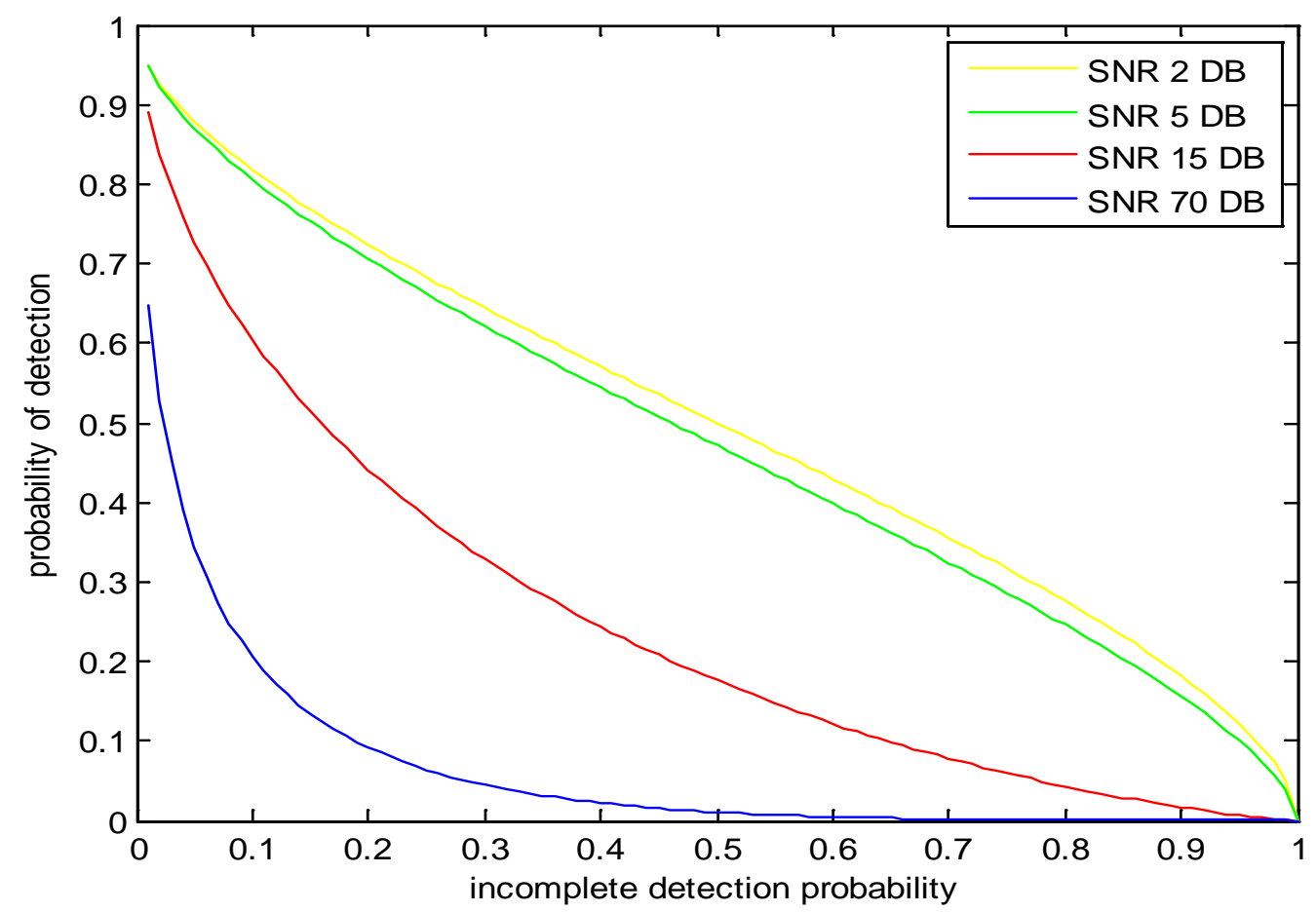

Fig.10. Probability of detection compared to incomplete detection probability for various SNRs.

Results show that the spectrum sensing performance is quite good according to the Neyman-Pearson approach. It is indicated that the detection performance can be significantly reduced at lower SNR values. The main reason of this is the hidden primary user problem. Since primary user is signal exposed to action such as damping, blocking, etc. because of secondary user's location, it is shown that possibility of incorrect decision making increases at very low SNR values (usually less than $10 \mathrm{~dB}$ ).

The limited availability of the frequency spectrum makes it difficult for unlicensed users to locate in the spectrum. Dynamic frequency allocation to unlicensed users can be done through cognitive radio. In this study, energy based detection process is proposed for the detection of empty frequency bands in the spectrum and the possibility of false detection is reduced. With this method, effective spectral sensing can be performed especially for channels with high SNR value.

\section{References}

S. Haykin, D.J.Thompson, J.H.Reed (2009). Spectrum Sensing for Cognitive Radio. Proceeding of IEEE, vol.97, no.5, pp. 849877,

J. Mitola G. Q. Maguire (1999). Cognitive Radio: making software radios more personel ERRR Personal Communications, vol6, no.4, pp. 13-18

FCC (Federal Communications Commission) (2002). Spectrum policy task force report. Technical Report, 02-135, 2002.

S. İngök (2002). Bilişsel Radyoda Özdeğer Tabanlı Spektrum Sezme Yöntemleri. Msc Thesis, İstanbul Technical University, August

F.K. Jondral (2005). Software-Defined Radio-Basics and Evolution to Cognitive Radio. EURASIP Journal on Wireless Communications and Networking, vol. 2005, no. 3, pp. 275-283.

E. Tuna, M.,Karagöz (2012). Gelecek Nesil Ağlar İçin Spektrum Tahsisinde Yeni Bir Yaklaşım: Bilişsel Radyo. International Journal of Engineering Research and Development, vol.4, no.1,

C. Pham, N.H. Tran, C.T. Do, C, S. Moon, C.S. Hong (2014). Spectrum Handoff Model based on Hidden Markov Model in Cognitive Radio Networks. Conference Proceedings, IEEE International Conf. on Information Networking, Phuket, pp. 406 - 411.

L. Khalid, A. Anpalagan (2010). Emerging cognitive radio technology:Principles, challenges and opportunities. Computer and Electrical Engineering, vol.36, no.2 pp.358-366. 
A. Lertsinsrubtavee, A., Malouch, S. Fdid (2014).Hybrid Spectrum Sharing Through Adaptive Spectrum Handoff for Cognitive Radio Networks. IEEE Networking Conference, Trondheim, pp. 1 - 9.

I.F. Akyildiz, W.Y. Lee, K.R. Chowdhury (2009). CRAHNs: Cognitive radio ad hoc networks. Ad Hoc Networks, vol.7, no.5, pp.810-836.

S. Atapattu, C. Tellambura, H. Jiang (2011). Spectrum Sensing via Energy Detector in Low SNR. IEEE International Conf. on Communications, Kyoto, Japan.

S.Y. Lien, C.C. Tseng, K.C. Chen (2008). Carrier Sensing based Multiple Access Protocols for Cognitive Radio Networks. IEEE International Conf. on Communications, Beijing, China.

F.F. Digha, M.S. Alouini, M.K. Simon (2007). On the Energy Detection of Unknown Signals over Fading Channels. IEEE Transactions on Communications, vol.55, no.1, pp.21-24, 21-24.

Emrullah GAZIOGLU (2015). Bilissel Radyo Aglarında Ust Sezgiseller İle Kanal Atama Problemının Çözülmesı. İstanbul Teknık Ünıversıtesı Fen Bılımlerı Enstıtüsü, Yüksek Lisans Tezi. 